\title{
Key Considerations in Integrated HIV-TB Services in the Prevention of Mother-to-Child Transmission: A focus on a Tertiary Health Facility in Lagos, Nigeria
}

\author{
Stellamaris Moronkeji ${ }^{1}$, Ebenezer Obi Daniel ${ }^{1, *}$, Adedoyin Ogunyemi ${ }^{2}$, \\ Ogunnaike Adewale Adeyemi ${ }^{3}$, Onyezue Okechukwu Innocent ${ }^{1}$, Osato Harriet Obasuyi ${ }^{4}$, \\ Israel Olukayode Popoola ${ }^{5}$ \\ ${ }^{1}$ Department of Public Health, School of Public Health, Texila American University, Georgetown, Guyana South America \\ ${ }^{2}$ Department of Community Health and Primary Care, College of Medicine, University of Lagos, Lagos, Nigeria \\ ${ }^{3}$ Department of Health Policy and Management, Faculty of Public Health, University of Ibadan, Ibadan, Nigeria \\ ${ }^{4}$ Department of Health Safety and Environmental Education, Faculty of Education, University of Benin, Benin, Nigeria \\ ${ }^{5}$ Department of Epidemiology and Community Health, Faculty of Medicine, University of Ilorin, Ilorin, Nigeria
}

Email address:

dannypressy@yahoo.com (E. O. Daniel)

${ }^{*}$ Corresponding author

\section{To cite this article:}

Stellamaris Moronkeji, Ebenezer Obi Daniel, Adedoyin Ogunyemi, Ogunnaike Adewale Adeyemi, Onyezue Okechukwu Innocent, Osato Harriet Obasuyi, Israel Olukayode Popoola. Key Considerations in Integrated HIV-TB Services in the Prevention of Mother-to-Child Transmission: A focus on a Tertiary Health Facility in Lagos, Nigeria. European Journal of Preventive Medicine.

Vol. 7, No. 5, 2019, pp. 84-88. doi: 10.11648/j.ejpm.20190705.12

Received: September 5, 2019; Accepted: September 24, 2019; Published: October 10, 2019

\begin{abstract}
The need to prevent vertical transmission of HIV to a new born and the imperativeness of instituting a functional integrated HIV and Tuberculosis (TB) services across health facilities will be a landmark public health intervention that will improve the quality of life of millions. This survey is a descriptive study in which respondents (HIV positive pregnant women enrolled for the prevention of mother to child transmission service) were purposively selected based on consent to participate across multiple points at the Lagos State University Teaching Hospital. The 27 respondents participated in the study. About 50\% of the respondents were between 18-30 years old with majority having secondary school education or more. The respondents are mostly married and generally knowledgeable about the mode of transmission of HIV/AIDS, TB and antiretrovirals. The major considerations cited by the respondents include; care beyond hospital settings by community health workers (home care and visitation), counseling, health education and promotion, TB screening while "increased stigma \& discrimination" and "fear of meeting known persons" were identified as possible disadvantages. The survey revealed and highlighted the key considerations in implementing HIV-TB integrated services into the PMTCT services. Improved training for health workers for effective management of the increased work burden is recommended.
\end{abstract}

Keywords: Integrated Services, HIV, Tuberculosis (TB), PMTCT

\section{Introduction}

The HIV epidemic has been a public health issue of global scale since its first case was recorded. Currently, about 37.9 million people are living with HIV (PLWH) globally with Africa contributing about $70 \%$ of the global burden while only $62 \%$ of the PLWH were receiving

treatment in 2018 [1]. In 2018, there were about 14-23 million newer infections globally with Africa accounting for about 800,000-1.5 million of these infections. The prevalence of HIV among adults (15-49 years) in Africa is 3.9 which is about 4.9 times the global prevalence among 
the same age group with 0.8 [2].

Tuberculosis (TB) ranks as the $8^{\text {th }}$ leading cause in Low and Middle Income Countries (LMICs) among adults 15-59 years old [3] despite being a curable disease, in most instances, with drug combinations that have been available since 1950s-1980s. Drug-susceptible TB can be cured in 6 months with first-line dugs while treatment of multidrugresistant TB requires second-line drugs that are more costly, with severe side effects and a drug regimen of up to 2 years. [4]

HIV has been documented as a risk factor for TB with over $10 \%$ of the annual TB cases occurring among HIV positive individual. Africa contributes about $80 \%$ of the global HIVTB epidemic where almost $35 \%$ of the TB cases are among people that are HIV positive [5]. Effective management, prevention and treatment, of HIV will serve as an effective tool in TB control [6] and thus the need for integrated services.

To generate increased insights to this integrated service especially in the Low- and Medium-Income Countries like Nigeria, this survey aimed at documenting opinions and perceptions of HIV positive women, as a case study, which will serve as considerations for researchers and policymakers as they look to institute HIV-TB-PMTCT integrated services under one roof.

\section{Method}

This was a descriptive survey implemented at the Lagos State-owned tertiary facility among HIV positive pregnant women enrolled for the prevention of mother to child transmission of HIV service. The respondents who gave their consent were purposively selected consecutively until $50 \%$ of the total enrollee in the facility at the time of the survey was reached. In total, 27 positive pregnant women participated in this survey. The semi-structured questionnaire used for data collection was written in English; however, the data collectors were trained to collect the data in English, pidgin and Yoruba Languages being the three prevalent languages in the survey settings. Data collected was analyzed using SPSS v21 software and were presented in frequency and percentages. The number of facilities and respondents interviewed for this survey may serve as limitations to the generality of the findings of this survey. Ethical clearance was sought and obtained from the Ethics Committee of the Texila American University Georgetown, Guyana, South America.

\section{Result}

\subsection{Socio-demographic Characteristics of Respondents}

Half of the respondents were 18-30 years old with majority (78\%) having secondary school education. While $40 \%$ of the respondents were single, $82 \%$ were Christians.
Table 1. Socio-demographics of respondents.

\begin{tabular}{lll}
\hline Characteristics & Frequency $(\mathbf{n = 2 7 )}$ & Percentage (\%) \\
\hline Age of Adult (years) & & \\
$18-30$ years & 14 & $(51.9)$ \\
$31-40$ years & 10 & $(37.0)$ \\
41 years and above & 3 & $(11.1)$ \\
Education & & \\
Primary & 1 & $(3.7)$ \\
Secondary & 21 & $(77.8)$ \\
Graduate & 5 & $(18.5)$ \\
Marital Status & & \\
Single & 11 & $(40.7)$ \\
Married & 15 & $(55.6)$ \\
Divorced & 1 & $(3.7)$ \\
Widow & & \\
Religion & & \\
Christianity & 22 & $(81.5)$ \\
Islam & 5 & $(18.5)$ \\
\hline
\end{tabular}

\subsection{Knowledge of Respondents About Mode of Transmission of HIV}

The respondents have a good knowledge of the mode of transmission of HIV/AIDS. Majority of them were aware of "transfusing of infected blood" and "sharing of infected sharps" as modes of transmissions of HIV. Unprotected sexual intercourse with a HIV infected person was only reported by about $60 \%$ of the respondents.

Table 2. Knowledge of mode of transmission of HIV.

\begin{tabular}{lll}
\hline Mode of spreading HIV & Frequency $(\mathbf{n}=\mathbf{2 7})$ & Percentage $(\%)$ \\
\hline Unprotected Sexual Intercourse & 16 & $(59.3)$ \\
Blood Transfusion & 25 & $(92.6)$ \\
Unsterile Instrument & 23 & $(85.2)$ \\
MTCT & 19 & $(70.4)$ \\
\hline
\end{tabular}

\subsection{Respondents Awareness on the Importance of Antiretroviral}

Table 3 below revealed the importance of antiretroviral therapy according to the respondents and most respondents admitted that "it prevents death from HIV/AIDS complications" although a few (35\%) still believes antiretroviral will cure HIV eventually.

Table 3. Importance of antiretroviral to respondents.

\begin{tabular}{lll}
\hline Variable & $\begin{array}{l}\text { Frequency } \\
(\mathbf{n = 2 7 )}\end{array}$ & $\begin{array}{l}\text { Percentage } \\
(\mathbf{\%})\end{array}$ \\
\hline Drug to prevent transmission to baby & 13 & $(50.0)$ \\
Drug to cure HIV & 9 & $(34.6)$ \\
Drug to prevent death from HIV/AIDS & 22 & $(84.6)$ \\
Works effectively with optimal adherence & 17 & $(65.4)$ \\
\hline
\end{tabular}

\subsection{Expected Care and Supports of Respondents About Health Workers}

As revealed in table 4 the majority $(85 \%)$ of the respondents revealed that they will "like to be visited by healthcare workers" (as shown in table 4) but only $48 \%$ actually reported being visited by health workers. The expectation of the respondents was majorly on consistent health education $(87.5 \%)$ and support on the antiretroviral therapy $(68.8 \%)$. 
Table 4. Expectations of the respondents on the healthcare workers.

\begin{tabular}{lll}
\hline Variable & Frequency $(\mathbf{n}=\mathbf{2 7})$ & Percentage (\%) \\
\hline Would like to be visited by Health Care Workers & \multicolumn{2}{c}{$(85.2)$} \\
Yes & 23 & $(14.8)$ \\
No & 4 & $(48.2)$ \\
Ever Visited by Health Care Workers & 13 & $(51.8)$ \\
Yes & 14 & $(87.5)$ \\
No & & $(68.8)$ \\
Expected support from Healthcare Worker & 14 & $(37.5)$ \\
Health Education & 11 & \\
Support for antiretroviral treatment & 6 & \\
TB directly observed therapy (DOT) supervision & & \\
\hline
\end{tabular}

\subsection{Knowledge of Respondents About PMTCT}

Table 5 below shows the fact that HIV "can be transmitted to a newborn through breastfeeding" is known by most (79\%) of the respondents while about a third (32\%) doesn't know whether Mother-to-Child Transmission is preventable.

Table 5. The knowledge of PMTCT services.

\begin{tabular}{|c|c|c|c|}
\hline Variable & Yes $(\%)$ & No $(\%)$ & Don't know (\%) \\
\hline Mothers to Child transmission of HIV/AIDS possible & $14(73.7)$ & $1(5.3)$ & $4(21.0)$ \\
\hline HIV can be transmitted through Breastfeeding & $15(78.9)$ & $3(15.8)$ & $1(5.3)$ \\
\hline Baby born of HIV positive mother are to be tested for HIV & $13(68.4)$ & $4(20.1)$ & $2(10.5)$ \\
\hline MTCT is preventable & $12(63.2)$ & $1(5.3)$ & $6(31.6)$ \\
\hline
\end{tabular}

\subsection{Respondents Opinions About TB}

According to table 6 below, all the respondents reported that the same health worker serves as their DOT and antiretroviral treatment supporter with majority revealing that they have been taught on infant feeding options (96\%) and importance of using condoms to avoid re-infection (85\%).

Table 6. Respondents reports on TB.

\begin{tabular}{|c|c|c|}
\hline \multirow{2}{*}{ Variables } & Yes & No \\
\hline & $\mathbf{n}(\%)$ & $\mathbf{n}(\%)$ \\
\hline Does your DOT supporter also support you for antiretroviral (ARV) treatment? & $27(100.0)$ & \\
\hline Did a health worker talk to you about the importance of using condoms during pregnancy to avoid re-infection? & $23(85.2)$ & $4(14.8)$ \\
\hline Did a health worker talk to you about infant feeding options? & $26(96.3)$ & $1(3.7)$ \\
\hline Did you start your TB treatment here? & $13(52.0)$ & $12(48.0$ \\
\hline
\end{tabular}

\subsection{Views of Respondents on the Advantages of Having the HIV-TB-PMTCT in One Setting}

As highlighted in table 7 below, most of the respondents reported "save cost of transportation" as the main advantage of having the HIV-TB-PMTCT services in the same setting with about a quarter (25\%) viewing "health status known only to doctors and nurses" as an advantage.

Table 7. Advantages of HIV-TB-PMTCT in one setting.

\begin{tabular}{lll}
\hline $\begin{array}{l}\text { Advantages of having services at } \\
\text { same clinic }\end{array}$ & $\begin{array}{l}\text { Frequency } \\
(\mathbf{n}=\mathbf{2 7})\end{array}$ & $\begin{array}{l}\text { Percentage } \\
(\mathbf{\%})\end{array}$ \\
\hline Save Cost of Transportation & 23 & $(85.2)$ \\
Treatment Punctuality & 13 & $(48.1)$ \\
Remove worries and depression & 2 & $(7.4)$ \\
Patients' Health status is known only to & 7 & $(25.9)$ \\
Doctors and Nurses in same clinic & & $(40.7)$ \\
It saves time & 11 & \\
\hline
\end{tabular}

\subsection{Views of Respondents on the Disadvantages of Having the HIV-TB-PMTCT in One Setting}

With respect to table 8 , over $70 \%$ of the respondents viewed "long queue" which results in time wasting and "increased discrimination and stigma" as the major disadvantages of the HIV-TB-PMTCT in one setting.

Table 8. Disadvantages of HIV-TB-PMTCT in one setting

\begin{tabular}{lll}
\hline $\begin{array}{l}\text { Disadvantages of having services at same } \\
\text { clinic }\end{array}$ & $\begin{array}{l}\text { Frequency } \\
(\mathbf{n = 2 7 )}\end{array}$ & $\begin{array}{l}\text { Percentage } \\
(\mathbf{\%})\end{array}$ \\
\hline Fear of meeting people you know & 12 & $(44.4)$ \\
Increased discrimination and Stigma & 20 & $(74.1)$ \\
Too much people in the queue/time wasting & 21 & $(77.8)$ \\
\hline
\end{tabular}

\subsection{Perceptions of Respondents About Health Workers Support}

Most (63\%) of the respondents (as revealed in table 8) perceived that the health workers are very attentive when attending to them and about half $(51 \%)$ reported receiving 
adequate advice on proper usage of ARV/TB drug. However, about a quarter $(25 \%)$ of the respondents reported that they do not feel the health workers are reliable and some $(15 \%)$ reported to be being addressed roughly by the health workers.

Table 9. Perceptions about health workers supports.

\begin{tabular}{lll}
\hline Variables & $\begin{array}{l}\text { Frequency } \\
(\mathbf{n = 2 7 )}\end{array}$ & $\begin{array}{l}\text { Percentage } \\
(\mathbf{\%})\end{array}$ \\
\hline Very attentive & 17 & $(63.0)$ \\
Advise on ARV / TB drugs usage & 14 & $(51.9)$ \\
Address patients roughly & 4 & $(14.8)$ \\
Some of them are not reliable & 7 & $(25.9)$ \\
\hline
\end{tabular}

\section{Discussion}

The respondents of this survey showed a good knowledge about the modes of transmission of HIV mostly through blood transfusion, infected sharps and MTCT although this varied from Platten and Ahmed et al reports which despite revealing their respondents had high knowledge of the modes of transmission, transmission through unprotected sex and infected sharps were mostly reported. [7, 8] This difference may emanate from profile of respondents since most of our respondents had secondary school education while participants of the study of Platten and Ahmed et. al are medical or pharmacy students in tertiary institutions.

The knowledge of the importance of antiretroviral therapy by our respondents is fair since only its ability to prevent death from HIV/AIDS complications was well reported. Similar survey in the same facility among PLHIV reported good knowledge about the importance of ART among their respondents [9]. This difference could be because the respondents in our survey are HIV positive pregnant in PMTCT programs whereas in the referenced study [9], respondents were HIV positive individuals of both sexes. Other surveys $[10,11,12]$ respondents also showed good knowledge of ART. These findings show that for HIV-TBPMTCT integrated services to be effective, increasing the knowledge of clients about services being received should be a priority.

The opinions of respondents about TB services received are generally positive which may be due to the high health education reported by respondents of this survey. Kigozi et al. also reported similar positive attitudes among respondents towards TB treatment received and while Grace W. et al participants perceived TB as a contagious disease they had a wrong notion of the cause and mode of transmission of TB despite already being on treatment $[13,14]$. Buregyeya et al, and Wandwalo et al, also reported similar findings $[15,16]$. This disparity in knowledge - positive awareness about TB, wrong knowledge of TB mode of transmission and cause, which can affect treatment outcome should be targeted through sustained patient education and awareness creation in the community especially as implementers institute HIVTB-PMTCT integrated services.

A few of the respondents had some negative perception about the health workers while majority had positive perception about the health workers attitude. Majority of our respondents described the health workers as "very attentive" and "provided advice on ARV/TB drugs usage" whereas a Viet Names survey revealed that no information was provided on Highly Active Antiretroviral Therapy (HAART) among its respondents (HIV positive pregnant women) [17]. Our findings also contradict that of a Kenyan study whose respondents revealed that counseling lasted less than 5 minutes and they could not recall its content [18] Conflicting information from health workers, internet and other media were also reported in a Jamaican study. [19]

Majority of our respondents cited "too much people in the queue" and "increased stigma and discrimination" as disadvantages. Laura $\mathrm{F}$ described stigma and discrimination as the most important barrier as it can emanate from friends, families, societies, health care settings and sadly, from partners [20]. Stinson, Mepham, Nassali and Teeraratkul et al also reported varying degrees of societal stigma being faced by women attending PMTCT services. [21, 22, 23, 24]

\section{Conclusion}

This survey was able to highlight some considerations for policy makers and implementers as they view to institute HIV-TB-PMTCT integrated services. Improving knowledge of HIV positive clients through emphasis on HIV modes of transmission and importance of antiretroviral therapy; training and retraining of health workers on health education messages dissemination and improved attitudes towards clients while also increasing the numbers of health workers at facilities and improving their remuneration, all of which will be highly beneficial.

\section{Recommendation}

1. For effective incorporation of PMTCT into the HIV-TB services, number of health workers should be increased at these facilities

2. Enabling environment to cater for the increased number of patients attending these facilities should be instituted

3. Regular training and retraining of health workers on the global updates of PMTCT and TB management strategies and improvement of health workers attitudes towards clients

\section{References}

[1] https://www.who.int/hiv/data/en/

[2] http://apps.who.int/gho/data/view.main.22500WHOREG?lang $=$ en

[3] Lopez AD (2006). Global burden of disease and risk factors. New York, Oxford University Press and The World Bank, 2006.

[4] Multidrug and extensively drug-resistant TB (M/XDR-TB) (2010) global report on surveillance and response. Geneva, World Health Organization, 2010 (WHO/HTM/TB/2010.3). 
[5] The Global plan to Stop TB 2011-2015. (2010) Transforming the fight towards elimination of Tuberculosis. World Health Organization.

[6] Corbett E, Watt C, Walker Net (2003) The growing burden of tuberculosis: global trends and interactions with the HIV epidemic. Archives of Internal Medicine, 163, 1009-1021.

[7] Platten (2014):: Knowledge of HIV and factors associated with attitudes towards HIV among final-year medical students at Hanoi medical university in Vietnam. BMC Public Health 2014 14: 265.

[8] Ahmed SI, Hassali MA, Bukhari NI, Sulaiman SA (2011): A comparison of HIV/AID Srelated knowledge, attitudes and risk perception between final year medical and pharmacy students: a cross sectional study. HealthMED 2011, 5 (2): 326-335.

[9] Kasumu LO, Balogun MR (2014). Knowledge and attitudes towards antiretroviral therapy and adherence pattern of HIV patients in southwest Nigeria. International Journal of $\begin{array}{llll}\text { Infection } & \text { Control } 2014 . & \text { V10.13. doi: }\end{array}$ 10.3396/IJIC.v10i3.024.14.

[10] Batamwita R, Moore DM, King R, Mills E, Stangl AL (2011). Assessment of antiretroviral therapy knowledge and willingness of persons with HIV to support its uptake in Uganda. Patient Prefer Adherence 2011; 5: 499-506. http://dx.doi.org/10.2147/PPA.S23289

[11] Boateng D, Kwapong GD, Agyei-Baffour P (2013). Knowledge, perception about antiretroviral therapy (ART) and prevention of mother-to-child transmission (PMTCT) and adherence to ART among HIV positive women in the Ashanti Region, Ghana: a cross-sectional study. BMC Women's Health 2013; 13: 2. http://dx.doi.org/10.1186/1472-6874-13-2

[12] Nachega JB, Lehman DA, Hlatshwayo D, Mothopeng R, Chaisson RE, Karstaedt AS (2005). HIV/AIDS and antiretroviral treatment knowledge, attitudes, beliefs, and practices in HIV-infected adults in Soweto, South Africa. $J$ Acquir Immune Defic Syndr 2005; 38 (2): 196-201. http://dx.doi. org/10.1097/00126334-200502010-00011

[13] Kigozi N. Gladys, J. Christo Heunis, Michelle C. Engelbrecht, André P. Janse van Rensburgand H. C. J. Dingie van Rensburg (2017) Tuberculosis knowledge, attitudes and practices of patients at primary health carefacilities in a South African metropolitan: research towards improved health education BMC Public Health (2017) 17: 795 DOI 10.1186/s12889-0174825-3.
[14] Grace Wambura Mbuthia, Charles Owour Olungah, Tom Gesora Ondicho (2018). Knowledge and perceptions of tuberculosis among patients in a pastoralist community in Kenya: a qualitative study. The Pan African Medical Journal (2018). doi: 10.11604/pamj.2018.30.287.14836.

[15] Buregyeya E, Kulane A, Colebunders R, Wajja A, Kiguli J, Mayanja H (2011). Tuberculosis knowledge, attitudes and health-seeking behaviour in rural Uganda. Int J Tuberc Lung Dis. 2011; 15 (7): 938-42. PubMed | Google Scholar.

[16] Wandwalo E, Mørkve O. (2000) Knowledge of disease and treatment among tuberculosis patients in Mwanza, Tanzania. The International Journal of Tuberculosis and Lung Disease. 2000; 4 (11): 1041-1046. PubMed | Google Scholar.

[17] Hardon, A. P. (2009). Preventing mother-to-child transmission of HIV in Vietnam and Indonesia: diverging care dynamics. Soc Sci Med, 2009; 69 (6): 838-45.

[18] Moth, I. A., A. B. Ayayo, and D. O. Kaseje (2005) Assessment of utilisation of PMTCT services at Nyanza Provincial Hospital, Kenya. SAHARA J, 2005; 2 (2): 244-50.

[19] Anderson, G. (2012). Community voices: barriers and opportunities for programmes to successfully prevent vertical transmission of HIV identified through consultations among people living with HIV. J Int AIDS Soc 2012; 15 (Suppl. 2): 17991.

[20] Laura Ferguson. Women's experiences in services for preventing the mother-to-child transmission of HIV: a literature review. World Health Organization 2013. $\mathrm{WHO} / \mathrm{HIV} / 2013.47$

[21] Stinson, K., L. Myer (2012) Barriers to initiating antiretroviral therapy during pregnancy: a qualitative study of women attending services in Cape Town, South Africa. Ajar - African Journal of AIDS Research, 2012; 11 (1): 65-73.

[22] Mepham, S. (2011) Challenges in PMTCT antiretroviral adherence in northern KwaZulu-Natal, South Africa. AIDS Care, 2011; 23 (6): 741-747.

[23] Nassali, M. (2009): Access to HIV/AIDS care for mothers and children in sub-Saharan Africa: adherence to the postnatal PMTCT program. AIDS Care, 2009; 21 (9): 1124-1131.

[24] Teeraratkul, A. (2005). Evaluating programs to prevent mother-to-child HIV transmission in two large Bangkok hospitals, 1999-2001. JAIDS Journal of Acquired Immune Deficiency Syndromes, 2005; 38 (2): 208-212. 